\title{
Hormone therapy increased incidence and severity of urinary incontinence in healthy postmenopausal women
}

Hendrix SL, Cochrane BB, Nygaard IE, et al. Effects of estrogen with and without progestin on urinary incontinence. JAMA 2005;293:935-48.

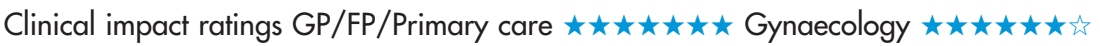

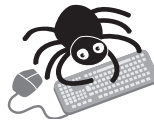

\section{METHODS}

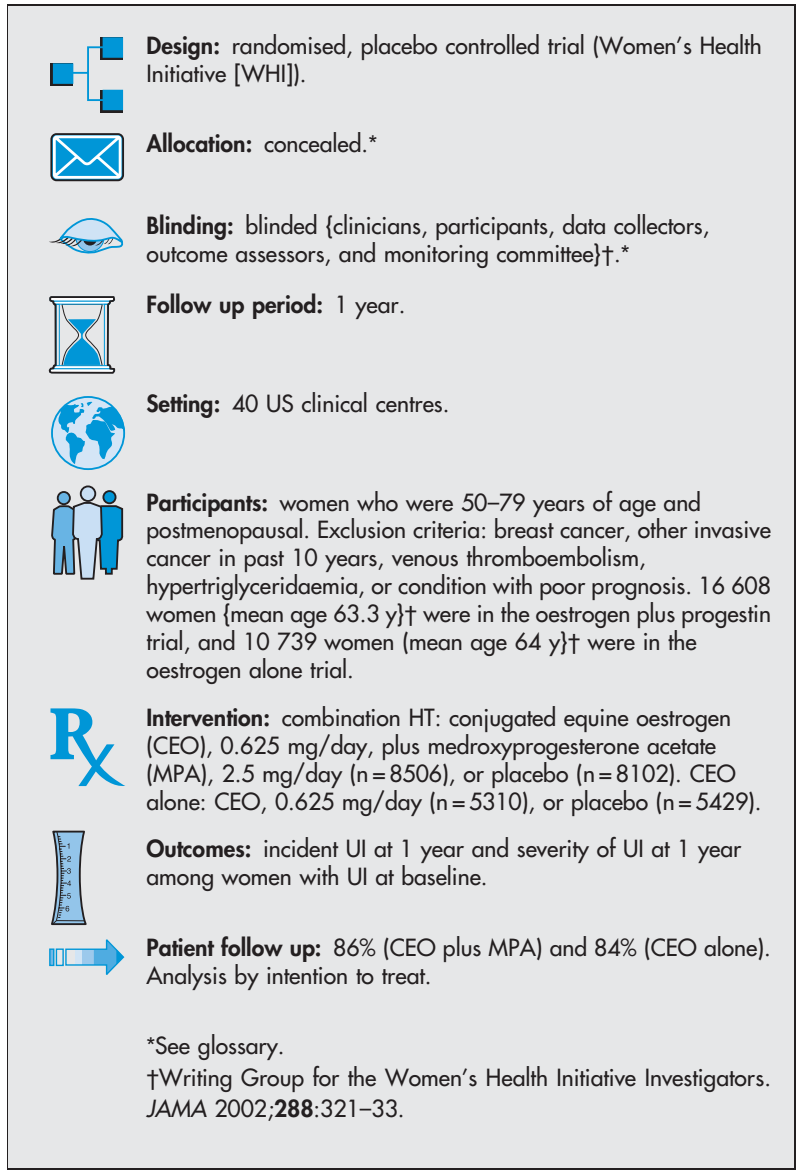

For correspondence: Dr S Hendrix, Wayne State University School of Medicine/Hutzel Women's Hospital, Detroit, MI, USA. shendrix@med. wayne.edu

Source of funding: National Heart, Lung and Blood Institute.

\section{MAIN RESULTS}

The table shows the results. See complete table at www.evidencebasedmedicine.com.

\section{CONCLUSION}

In healthy postmenopausal women, hormone therapy increased the incidence and severity of urinary incontinence.

\section{Commentary}

$\mathrm{T}$ he report by Hendrix et al is the latest surprising finding to come out of the WHI trials of HT in healthy postmenopausal women. $\mathrm{UI}$ is a common problem after menopause and increases steadily with age. Until recently, HT had been among recommended therapies for UI, based on a mixture of small trials, observational studies, and the documented benefits of oestrogen on genital symptoms such as atrophic vaginitis and dyspareunia. The WHI results, however, confirm earlier findings of the HERS trial, ${ }^{1}$ which reported that oestrogen and progestin were not only ineffective but actually worsened symptoms of existing UI. WHI extends those findings to unopposed oestrogen and to previously asymptomatic women, in whom HT increased incident UI.

The biological mechanisms remain to be elucidated, but these findings from 2 large, well done randomised controlled trials using validated measures of incontinence probably close the door on $\mathrm{HT}$ as a therapy for $\mathrm{UI}$. In retrospect, the increase in Ul after menopause seems primarily to be a function of age rather than hormonal changes. ${ }^{2}$ Clinicians should advise women about behavioural therapies such as pelvic exercises and weight loss and target additional therapies to the specific type of incontinence (stress $v$ urge). ${ }^{3}$

These findings probably don't affect the primary remaining indication for HT, treating bothersome menopausal symptoms. HT remains an option for younger women with troublesome hot flashes and sleep disturbances, since incontinence was uncommon in this trial and not clearly affected by HT in women closer to menopause. Clinicians should follow recommendations to use the lowest effective dose for the shortest time needed to relieve symptoms and periodically reassess need for therapy. David Atkins, MD, MPH Agency for Healthcare Research and Quality, Rockville, Maryland, USA 1 Grady D, Brown JS, Vittinghoff E, et al. Obstet Gynecol 2001;97:116-20.

2 US Department of Health and Human Services. NIH News March 23, 2005. www.nih.gov/news/pr/mar2005/od-23.htm (accessed 16 Jun).

3 Nygaard IE, Heit M. Obstet Gynecol 2004;104:607-20.

HT (conjugated equine oestrogen [CEO] with or without medroxyprogesterone acetate [MPA]) after menopause*

\begin{tabular}{llllll}
\hline Outcomes at 1 year & Trial & HT & Placebo & RRI (95\% CI) & NNH (CI) \\
\hline Incident stress urinary & CEO + MPA & $16 \%$ & $8.7 \%$ & $87 \%$ (61 to 118) & 14 (10 to 19) \\
incontinence (UI) & CEO alone & $17 \%$ & $8.5 \%$ & $115 \%(77$ to 162) & 11 (8 to 16$)$ \\
Incident urge UI & CEO + MPA & $11.4 \%$ & $10 \%$ & $15 \%(-1$ to 34) & $\begin{array}{l}\text { Not significant } \\
\end{array}$ \\
& CEO alone & $14 \%$ & $12 \%$ & $32 \%(10$ to 58$)$ & 27 (15 to 84$)$ \\
\hline & & Relative risk (CI) & \\
\hline Worsened amount of UI & CEO + MPA & $1.20(1.06$ to 1.36$)$ \\
Worsened frequency of UI & CEO alone & $1.59(1.39$ to 1.82$)$ & \\
& CEO + MPA & $1.38(1.28$ to 1.49$)$ & \\
& CEO alone & $1.47(1.35$ to 1.61$)$ & \\
\hline
\end{tabular}

*HT = hormone therapy. Other abbreviations defined in glossary; RRI, NNH, and Cl calculated from data in article. 